\title{
The history of cancer pain and bone-targeted agents: I 0 most commonly asked questions
}

This article was published in the following Dove Press journal:

Cancer Management and Research

\section{Cláudia Margarida Pereira \\ Vieira ${ }^{1-3}$ \\ Maria Fragoso ${ }^{1,4}$ \\ Marta Ferreira' \\ Filipa Ferreira Pereira' \\ Deolinda Pereira \\ Rui Medeiros 2,3,5,6 \\ 'Medical Oncology Department, Instituto Português de Oncologia do Porto Francisco Gentil (IPO- PORTO), Porto, Portugal; ${ }^{2}$ Research Center, Molecular Oncology Group Instituto Português de Oncologia do Porto Francisco Gentil (IPO-PORTO), Porto, Portugal; ${ }^{3}$ Faculty of Medicine, University of Porto, Porto, Portugal; ${ }^{4}$ Unit of Study and Treatment of Pain, Instituto Português de Oncologia do Porto Francisco Gentil (IPO-PORTO), Porto, Portugal; ${ }^{5}$ Biomedical Research Center, Faculty of Health Sciences, Fernando Pessoa University, Porto, Portugal; ${ }^{6}$ Research Department, Portuguese League Against Cancer, Porto, Portugal}

Correspondence: Cláudia Margarida Pereira Vieira

Medical Oncology Department, Instituto Português de Oncologia do Porto Francisco Gentil (IPO-PORTO), Rua Dr António Bernardino de Almeida, 4200-072 Porto, Portugal

Tel +35 I22 5084000 (ext 7627)

$\mathrm{Fax}+35$ I22 508400 I

Email claudia.vieira@ipoporto.min-saude.pt

\begin{abstract}
The prevalence of pain and skeletal complications of metastatic bone disease is high and an important factor, which contributes to decreased quality of life and low survival rate. Bone-targeted agents are well-established therapies to reduce the skeletal-related events in patients with bone metastasis. However, the analgesic effect of these medications is still controversial. The objective of this review is to summarize the existing evidence about the use of bone-targeted agents in the treatment of metastatic bone pain, trying to answer to the 10 most commonly asked questions in this matter. To achieve this goal, authors did a research of reviews published between January 2001 and January 2018, using the terms MeSH: "cancer pain" and bisphosphonates. The source used was the PubMed (NLM) database. The search yielded 36 reviews, but only 16 met the inclusion criteria. Even with the introduction of a new class of drugs, bisphosphonates and specially zoledronic acid are the most commonly used drugs in most oncology centers. Bisphosphonates and denosumab appear to be beneficial in preventing skeletal morbidity but their analgesic role and impact on quality of life and survival are not so well established.
\end{abstract}

Keywords: cancer pain, bisphosphonates, bone metastasis, palliative care, bone-targeted agents, denosumab

\section{Introduction}

The American Cancer Society estimates that $~ 50 \%$ of the new cases diagnosed every year involve tumors of the breast, prostate, lung, kidney, and thyroid. These tumors account for $80 \%$ of all skeletal metastases. ${ }^{1,2}$

At some stage of their disease, up to $90 \%$ of patients with cancer will experience pain, with a third rating the intensity of their pain as moderate to severe. ${ }^{3}$ Between $23 \%$ and $45 \%$ of patients with metastatic bone disease receive inadequate treatment for pain, which remains one of the most feared consequences for cancer patients. ${ }^{1}$

Bone involvement is an important complication of metastatic cancer and cause considerable morbidity, including severe pain, immobility and disability, pathologic fractures, hypercalcemia, and spinal cord compression. These problems, skeletal-related events (SREs), have a great impact on the patient's quality of life (QoL). ${ }^{2}$

Bisphosphonates (BPs) may reduce and/or delay the skeletal morbidity resulting from osteoporosis and metastatic bone disease (MBD). BPs have been used for over 15 years to improve the prognosis of patients with bone metastases from solid tumors. ${ }^{4}$

The first agent of this class, for which a clinical benefit for MBD was demonstrated, was clodronate. ${ }^{2}$ Pamidronate (PAM), the second generation of this class, is 
administered intravenously and has demonstrated clinical benefits in different SREs in several studies. ${ }^{5}$ As a result, it was approved in the USA and quickly became the international standard in metastatic breast cancer. ${ }^{2,6}$ However, administration of PAM has a prolonged infusion time ( 2 hours) and limited efficacy in metastatic bone pain, particularly in prostate cancer. ${ }^{7}$ Zoledronic acid (ZOL), the third generation, which can be administered in a 15-minute infusion, has proved to be at least as effective as PAM in preventing SREs in breast cancer and multiple myeloma in a direct comparison clinical trial. ${ }^{2,8,9}$ ZOL has an impact on bone pain in patients with breast and prostate cancer. ${ }^{6,10-12}$ However, the potential for renal toxicity with ZOL may limit its use. , $^{2,8,9,13-15}$

Controlled clinical trials have demonstrated that BP treatment, in addition to its benefits in terms of skeletal morbidity, can reduce bone pain, including opioid-refractory pain., ${ }^{4,16}$ In treating the worst pain reported by a patient, the main goal is decreasing the severity of symptoms and increasing functionality, with better QoL in general. ${ }^{17,18}$ The quantity and quality of scientific evidence related to new anticancer drugs are greater than those of the evidence for supportive care. The heterogeneity of outcomes employed is one contributor to this gap. ${ }^{19}$

The aim of this analysis is to summarize the evidence present in the reviews concerning the role of bone-targeted agents (BTAs), particularly BPs, in the treatment of metastatic bone pain and answer the 10 most commonly asked questions about these drugs. The main goal was to update the essential knowledge in the field representing an objective evidence-based summary about BTAs, for all clinicians.

\section{Materials and methods Review question}

This review and the analysis state the chance of pain reduction and bone complication reduction (SREs) with the use of BTAs in cancer patients. Data from survival rate, QoL, side effects, use of analgesics, and progression of cancer are also described.

\section{Methods of review}

Research of relevant reviews published between January 2001 and January 2018, using the MeSH terms: "cancer pain" and bisphosphonates. A reference list of all eligible reviews was identified.

The source used was the PubMed (NLM) database (but this included two reviews from Cochrane Library).

The inclusion criteria for selecting articles were: that the study 1) was conducted in adult patients; 2) was with reference to BPs or denosumab in the abstract; 3) reported efficacy of BPs or denosumab on pain and/or described side effects; and 4) was in English language.
Exclusion criteria were 1) papers reporting the use of BTAs only in noncancer pain, hematologic disease, or pediatric patients; 2) reviews relating only to neuropathic pain, radioisotopes, opioids, or other analgesic techniques.

Two independent investigators reviewed each article in order to determine the eligible ones and choose the 10 most asked questions about BTAs. The final text and the 10 answers were reviewed and approved by all authors.

\section{Ethical approval}

This article does not contain any studies with human participants performed by any of the authors.

\section{Results and discussion}

The flowchart of this review is presented in Figure 1. The selection process described above led to the inclusion of 17 clinical trials presented in Table 1.

\section{What is the mechanism of action of BPs and denosumab?}

Bone metastases are caused by upregulated osteoclastic activity, leading to increased bone resorption, and are a common source of pain. BPs are selective inhibitors of osteoclastic bone resorption. ${ }^{3}$ Osteoclasts are derived from circulating monocytes. Differentiation of monocytes to

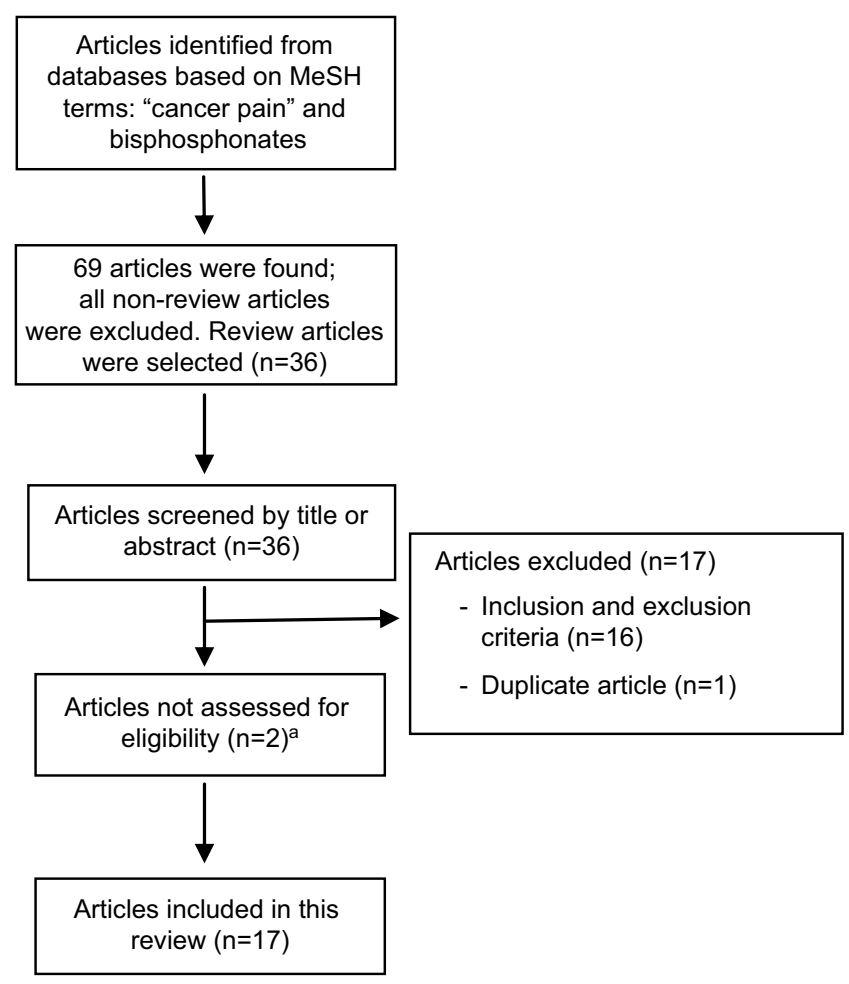

Figure I Flowchart of article selection.

Note: ${ }^{\text {aTwo }}$ of the articles were not assessed for eligibility because they were old articles and the library service of our institution could not access them. 
Table I Key message of reviews selected for this analysis

\begin{tabular}{|c|c|c|c|}
\hline $\begin{array}{l}\text { First authorl } \\
\text { year }\end{array}$ & Title & BTAs & Conclusions \\
\hline $\begin{array}{l}\text { McDonnell, } \\
200 I^{25}\end{array}$ & $\begin{array}{l}\text { Advances in cancer pain } \\
\text { management }\end{array}$ & $\begin{array}{l}\text { Pamidronate and } \\
\text { clodronate }\end{array}$ & $\begin{array}{l}\text { "Pamidronate has a definite place in cancer pain management. The } \\
\text { clinical benefit of newer, more potent oral or transdermal BPs with } \\
\text { lower side-effect profiles remains to be established."25 }\end{array}$ \\
\hline Lucas, $2002^{34}$ & $\begin{array}{l}\text { Recent advances in } \\
\text { pharmacotherapy for } \\
\text { cancer pain management }\end{array}$ & $\begin{array}{l}\text { Pamidronate, zoledronate, } \\
\text { and ibandronate }\end{array}$ & $\begin{array}{l}\text { "Finally, a more potent generation of BPs may lead to improved } \\
\text { pain relief for patients with bone metastases." } 34\end{array}$ \\
\hline Oura, $2003^{26}$ & $\begin{array}{l}\text { Clinical efficacy of BP } \\
\text { therapy for bone metastasis } \\
\text { from breast cancer }\end{array}$ & $\begin{array}{l}\text { Pamidronate, coladronate, } \\
\text { and minodronate }\end{array}$ & $\begin{array}{l}\text { "[...] patients with osteolytic bone metastases be treated not with } \\
\text { BP monotherapy, but with concurrent BP and systemic therapy. In } \\
\text { addition, it is also recommended that current standards of care for } \\
\text { cancer pain, analgesics, and radiotherapy should not be replaced } \\
\text { with BP therapy."26 }\end{array}$ \\
\hline Carr, $2004^{19}$ & $\begin{array}{l}\text { Evidence report on the } \\
\text { treatment of pain in cancer } \\
\text { patients }\end{array}$ & $\begin{array}{l}\text { Etidronate, } \\
\text { aminohydroxypropylidene } \\
\text { BP, pamidronate, and } \\
\text { clodronate }\end{array}$ & $\begin{array}{l}\text { "Many studies showed a positive effect, some showed no effect, } \\
\text { and no study showed a detrimental effect of BP therapy on skeletal } \\
\text { symptoms of metastatic disease or myeloma." } 19\end{array}$ \\
\hline Lussier, $2004^{22}$ & $\begin{array}{l}\text { Adjuvant analgesics in } \\
\text { cancer pain management }\end{array}$ & $\begin{array}{l}\text { Pamidronate, zoledronic } \\
\text { acid, and clodronate }\end{array}$ & $\begin{array}{l}\text { "Review of the evidence supporting the use of each class of } \\
\text { adjuvant analgesic for the treatment of pain in cancer patients and } \\
\text { provides a comprehensive outline of dosing recommendations, side } \\
\text { effects, and drug interactions."22 }\end{array}$ \\
\hline Davis, $2005^{20}$ & $\begin{array}{l}\text { Controversies in } \\
\text { pharmacotherapy of pain } \\
\text { management. }\end{array}$ & $\begin{array}{l}\text { Clodronate, pamidronate, } \\
\text { zoledronate and } \\
\text { ibandronate }\end{array}$ & $\begin{array}{l}\text { "BPs have a definite role in bone pain from metastasis. High doses } \\
\text { or loading doses can relieve opioid-refractory pain quickly." }{ }^{20}\end{array}$ \\
\hline $\begin{array}{l}\text { Kongsgaard, } \\
2005^{30}\end{array}$ & $\begin{array}{l}\text { Palliative treatment of } \\
\text { cancer-related pain }\end{array}$ & $\mathrm{BPs}$ & $\begin{array}{l}\text { "There is evidence to support that BPs provide an additive } \\
\text { analgesic effect beyond the treatment effect obtained with } \\
\text { standard analgesics. Current data indicate that BPs have a weak } \\
\text { or moderate effect on bone pain after } 4-12 \text { weeks of medication. } \\
{\left[\ldots . . .{ }^{30}\right.}\end{array}$ \\
\hline $\begin{array}{l}\text { O'Toole, } \\
2006^{\prime}\end{array}$ & $\begin{array}{l}\text { Metastatic bone cancer } \\
\text { pain: etiology and } \\
\text { treatment options }\end{array}$ & BPs & $\begin{array}{l}\text { "Advances in understanding the intricate pathway responsible } \\
\text { for pain generation and the addition of agents such as BPs to the } \\
\text { physician's armamentarium further assist in the management of } \\
\text { painful bone metastases."' }\end{array}$ \\
\hline $\begin{array}{l}\text { Mercadante, } \\
2007^{24}\end{array}$ & $\begin{array}{l}\text { Management of painful } \\
\text { bone metastases }\end{array}$ & $\begin{array}{l}\text { Etidronate, clodronate, } \\
\text { pamidronate, ibandronate, } \\
\text { zoledronic acid and } \\
\text { calcitonin. }\end{array}$ & $\begin{array}{l}\text { "According to new preclinical data, treatment of bone cancer pain } \\
\text { requires multidisciplinary therapies such as radiotherapy applied to } \\
\text { the painful area along with systemic treatment (hormone therapy } \\
\text { or chemotherapy) and supportive care (analgesic therapy and } \\
\text { BPs)."24 }\end{array}$ \\
\hline $\begin{array}{l}\text { Mercadante, } \\
2007^{23}\end{array}$ & $\begin{array}{l}\text { Pharmacologic management } \\
\text { of cancer pain in the elderly }\end{array}$ & BPs & $\begin{array}{l}\text { "Adjuvant analgesics, including antidepressants, antiepileptics, } \\
\text { corticosteroids, and BPs may help in the treatment of certain types } \\
\text { of chronic pain." } 23\end{array}$ \\
\hline Mitra, 2012 21 & $\begin{array}{l}\text { Adjuvant analgesics in } \\
\text { cancer pain: a review }\end{array}$ & $\begin{array}{l}\text { Pamidronate, zoledronic } \\
\text { acid, etidronate, } \\
\text { clodronate, alendronate, } \\
\text { denosumab, and calcitonin }\end{array}$ & $\begin{array}{l}\text { "[...] Specifically, the guidelines recommend the use of denosumab } \\
120 \mathrm{mg} \text { subcutaneously every } 4 \text { weeks, IV pamidronate } 90 \mathrm{mg} \text { over } \\
\text { no less than } 2 \text { hours, or zoledronic acid } 4 \mathrm{mg} \text { over no less than } 15 \\
\text { minutes every } 3-4 \text { weeks." }\end{array}$ \\
\hline Vardy, $2014^{3}$ & $\begin{array}{l}\text { Nonopioid drugs in the } \\
\text { treatment of cancer pain }\end{array}$ & $\begin{array}{l}\text { Pamidronate, ibandronate, } \\
\text { zoledronic acid, and } \\
\text { denosumab }\end{array}$ & $\begin{array}{l}\text { "BPs improve pain in patients with bony metastases in some tumor } \\
\text { types. Denosumab may delay worsening of pain compared with } \\
\text { BPs. Larger studies of longer duration are required to address } \\
\text { outstanding questions concerning the use of nonopioid analgesia } \\
\text { for stronger cancer pain." }\end{array}$ \\
\hline Chen, $2016^{32}$ & $\begin{array}{l}\text { Safety of denosumab vs } \\
\text { zoledronic acid in patients } \\
\text { with bone metastases: a } \\
\text { meta-analysis of randomized } \\
\text { controlled trials }\end{array}$ & $\begin{array}{l}\text { Denosumab and zoledronic } \\
\text { acid }\end{array}$ & $\begin{array}{l}\text { "Denosumab was safer in delaying or preventing SREs in patients } \\
\text { with bone metastases and prevented pain progression compared to } \\
\text { zoledronic acid in this meta-analysis." }{ }^{32}\end{array}$ \\
\hline
\end{tabular}


Table I (Continued)

\begin{tabular}{|c|c|c|c|}
\hline $\begin{array}{l}\text { First authorl } \\
\text { year }\end{array}$ & Title & BTAs & Conclusions \\
\hline $\begin{array}{l}\text { von Moos, } \\
2017^{31}\end{array}$ & $\begin{array}{l}\text { Improving quality of life } \\
\text { in patients with advanced } \\
\text { cancer: targeting metastatic } \\
\text { bone pain }\end{array}$ & $\begin{array}{l}\text { lbandronate, clodronate, } \\
\text { zoledronic acid, } \\
\text { pamidronate, denosumab }\end{array}$ & $\begin{array}{l}\text { "Treatments collectively referred to as BTAs can offer further } \\
\text { pain reduction. Initiation of therapy with BTAs is recommended } \\
\text { for all patients with metastatic bone disease because these agents } \\
\text { delay not only the onset of SREs but also the onset of bone } \\
\text { pain." }\end{array}$ \\
\hline $\begin{array}{l}\text { Porta-Sales, } \\
2017^{29}\end{array}$ & $\begin{array}{l}\text { Evidence on the analgesic } \\
\text { role of BPs and denosumab } \\
\text { in the treatment of pain } \\
\text { due to bone metastases: a } \\
\text { systematic review within } \\
\text { the European Association } \\
\text { for Palliative Care } \\
\text { guidelines project }\end{array}$ & $\begin{array}{l}\text { Clodronate, etidronate, } \\
\text { pamidronate, zoledronic } \\
\text { acid and denosumab }\end{array}$ & $\begin{array}{l}\text { "Evidence to support an analgesic role for BPs and denosumab is } \\
\text { weak. BPs and denosumab appear to be beneficial in preventing } \\
\text { pain by delaying the onset of bone pain rather than by producing an } \\
\text { analgesic effect per se." } 29\end{array}$ \\
\hline $\begin{array}{l}\text { O'Carrigan, } \\
2017^{28}\end{array}$ & $\begin{array}{l}\text { BPs and other bone agents } \\
\text { for breast cancer }\end{array}$ & BPs and denosumab & $\begin{array}{l}\text { "For early breast cancer patients, BPs reduce the risk of bone } \\
\text { metastases and provide an overall survival benefit compared to } \\
\text { placebo or no BPs and the preliminary evidence is suggestive of an } \\
\text { overall survival and disease-free survival benefit in postmenopausal } \\
\text { women [...]." } 28\end{array}$ \\
\hline $\begin{array}{l}\text { Macherey, } \\
2017^{27}\end{array}$ & $\begin{array}{l}\text { BPs for advanced prostate } \\
\text { cancer }\end{array}$ & BPs & $\begin{array}{l}\text { "Based on low-quality evidence, there may be no clinically relevant } \\
\text { difference in the proportion of men with pain response between } \\
\text { BPs and control regimens in men with bone metastases from } \\
\text { prostate cancer. BPs probably decrease the number of SREs and } \\
\text { disease progression." } 27\end{array}$ \\
\hline
\end{tabular}

Abbreviations: BP, bisphosphonate; BTA, bone-targeted agent; IV, intravenous; SRE, skeletal-related event.

osteoclasts requires macrophage-stimulating factor and nuclear factor kappa B (NF-kB; a transcription factor activated by tumor necrosis factor $\alpha$ and prostanoids). ${ }^{20}$ The receptor activator for NF-kB (RANK) is found on the surface of osteoclasts and the ligand is released by osteoblasts. After binding of the ligand and activation of NF-kB, it can activate osteoclasts. ${ }^{20}$ Osteoprotegerin prevents interaction of the RANK ligand (RANKL) with the receptor itself. Cancer disrupts the balance between the RANKL and osteoprotegerin release, in favor of the first, leading to osteoclast activation. ${ }^{20}$ BPs are pyrophosphate analogs in which the oxygen is replaced by a carbon atom with various side chains and their mechanism of action is quite complex. These agents bind to hydroxyapatite crystals, making it more difficult for osteoclasts to recognize unmineralized bone surfaces. ${ }^{3,20-22}$ They are released from the bone matrix during bone resorption and bind preferentially at sites of active bone metabolism. ${ }^{1,23,24}$ BPs are readily ingested by osteoclasts, inhibiting them to participate in future bone resorption activity. ${ }^{21,25}$ They can decrease osteoclast activity by decreasing osteoclast progenitor cells and increasing osteoclast apoptosis, reduce inflammatory cytokine production, and prevent metalloproteinase secretion. ${ }^{1,3,20,23,24} \mathrm{ZOL}$ is a potent inhibitor of osteoclastmediated bone resorption and it increases bone mineral density in men receiving androgen deprivation therapy. ${ }^{24}$ Denosumab is a fully human monoclonal antibody against the cytokine RANKL. RANKL is involved in tumor cell migration and is a mediator of osteoclast differentiation and activation. ${ }^{3}$

\section{Can BTAs delay cancer spread?}

Cancer pain secondary to bone metastasis is related with periosteum stretching and the release of inflammatory mediators like histamine, bradykinin, and prostaglandins. Bone metastasis may cause individuals to become more prone to the development of pathologic fractures. ${ }^{1,21}$ BPs have antiosteoclastic activity and may also suppress progression of bone metastases. They exhibit antiangiogenic properties and immunomodulator effects and may inhibit the mevalonate pathway, which can alter cell activity and apoptosis. ${ }^{1,24}$ When cancer cells have spread to bone, the normal homeostasis between osteoclasts and osteoblasts is disrupted. A vicious circle starts with the secretion of interleukins 1 and 6, parathyroid hormone-related protein, transforming growth factor-alpha, and prostaglandins by cancer cells, which 
induce osteoclasts to proliferate. ${ }^{21}$ This process leads to a net loss of bone, secondary to increased osteoclast and decreased osteoblast activity. ${ }^{21}$ Intravenous (IV) BP therapy can significantly reduce SREs and improve bone metastases in some patients. ${ }^{23,26}$ They lead to effective treatment for osteoporosis and osteoporotic complications, which is beneficial to bone health. ${ }^{20,23}$ The anticancer treatment and supportive care for cancer pain should not be stopped if patients started BTAs. Since 2003, American Society of Clinical Oncology (ASCO) guidelines recommend that lytic bone metastases should be treated with systemic therapy and concurrent BP. ${ }^{26}$ Cochrane systematic review in prostate cancer found that BPs probably decreased the number of men affected by disease progression, with 36 fewer men (per 1,000) with disease progression. ${ }^{27}$ In adjuvant setting, in early breast cancer patients, a Cochrane systematic review concludes that BPs probably lowered the risk of cancer spreading to the bone, but the survival benefit was low and related to the menopausal status (benefit to postmenopausal women). Further studies on this point and the data on survival rate (and other important outcomes) from denosumab trials are awaited. ${ }^{28}$ In advanced breast cancer without bone metastases, the period was insufficient for relevant conclusions. ${ }^{28}$

\section{Can BTAs control cancer pain?}

BTAs (particularly BPs and denosumab) are well-established therapies to reduce the frequency and severity of SREs in patients with MBD. ${ }^{19,26,29}$ A Cochrane review (2,806 patients with breast cancer) reported a reduction in SREs of $15 \%$ when comparing BPs with either placebo or no BPs. ${ }^{3,30}$ However, the analgesic effect of these drugs on bone pain is considered uncertain by some authors. ${ }^{29}$ Many years ago, BPs started to be used to treat malignant hypercalcemia and prevent complications in MBD. ${ }^{1,24,25}$ Then their effect of decreasing bone pain was reported..$^{21}$ Nowadays, it is well established that BTAs contribute to pain relief and reduce strong opioid use. Although studies of BTAs have not been designed to assess the speed of onset of pain relief, it is possible to note a significant effect on pain scores as early as 1-4 weeks after initial treatment. ${ }^{20,31} \mathrm{ZOL}$ has been proved to be highly effective in patients with bone metastases from prostate cancer, with statistically significant reductions in skeletal morbidity, including bone pain. ${ }^{1,24}$ Denosumab has also demonstrated efficacy in relation to pain palliation. In patients with bone metastases, the analyses of data from three Phase III studies showed that denosumab delayed the onset of moderate/severe pain by a median of 1.8 months $(95 \%$ CI $0.76-0.92 ; P<0.001)$ when compared to ZOL. And also, progression to strong opioid use and decrease in QoL was less common with denosumab $(P<0.05) .{ }^{31}$ A 2017 systematic review concluded that evidence to support an analgesic role for BPs and denosumab is still nowadays weak. Although, in spite of their lack of analgesic effect per se, they appear to be beneficial in delaying the onset of bone pain. ${ }^{29}$ For patients with opioid-resistant bone pain, a loading-dose approach with ibandronate can reduce pain within days (eg, $4 \mathrm{mg}$ IV -4 days or $6 \mathrm{mg}-3$ days). The loading dose technique has not yet been evaluated for other BPs or denosumab. ${ }^{20,31}$ For patients already experiencing widespread bone pain, BTAs may offer additional pain relief to that provided by opioids and radiotherapy or other local/regional analgesic techniques. Treatment of bone cancer pain requires a multidisciplinary team and should be personalized according to the patient's clinical condition, life expectancy, and QoL. Therapies such as radiotherapy can be applied to the painful region along with systemic treatment (hormone therapy or chemotherapy) and supportive care (analgesic therapy and BPs). In some selected cases, the use of radioisotopes (like samarium lexidronam, 153Sm-EDTMP) and other noninvasive or minimally invasive techniques may be useful for metastatic bone pain palliation. ${ }^{23,31}$ Two Cochrane systematic reviews were recently published, one on breast cancer and the other on prostate cancer. ${ }^{27,28}$ The prostate cancer review ( $876 \mathrm{men}$ ) concluded that BPs reduced pain in 40 more men per 1,000 and reduced SREs (less 58 per 1,000). No clear differences in the number of men who had decreased use of pain killers or had increased in survival rate were found. ${ }^{27}$ The Cochrane systematic review for women with metastatic breast cancer enrolled 10,853 participants. BPs reduced complications (fractures and bone pain) but did not appear to increase survival rate. Denosumab reduced the risk of complications compared to BPs. ${ }^{28}$ The ASCO guidelines recommend that patients with osteolytic bone metastases should be treated with systemic therapy and BP. Analgesics and radiotherapy should not be replaced with BP therapy because of their easy access, low price, and synergic effect in pain palliation. ${ }^{26}$

\section{Does BTAs treatment improve QoL?}

PAM IV improves QoL by delaying the onset of skeletal events by $45 \%$, decreasing vertebral fracture by $60 \%$, and reducing the need of bone surgery by $52 \%$ and radiation by $45 \% .{ }^{25}$ Oral PAM has a lower bioavailability. ${ }^{25,26}$ The relation of pain control to QoL has not been studied comprehensively. The quantity and quality of scientific evidence of the treatment of cancer and other high-impact conditions are much greater than those of the evidence related to cancer pain 
relief. ${ }^{32}$ Early use of BTAs in patients with no pain or only mild pain can improve QoL by delaying pain progression. ${ }^{31}$ The loading dose ibandronate relieves opioid-refractory bone pain within 7 days and seems to improve QoL and physical function. Even ibandronate administered orally reduced bone pain from breast cancer in a randomized controlled trial, with opioid sparing and improved QoL. ${ }^{20}$ For breast cancer patients, a Cochrane systematic review refers that QoL scores were slightly better for women receiving BPs. There was no increase in survival rate from denosumab (but only one study collected this data). ${ }^{28}$

\section{Are BTAs recommended only for MBD of breast cancer, prostate cancer, and/or multiple myeloma?}

Data from pain relief and BTAs treatment have been mainly assessed from studies including patients with only breast cancer, prostate cancer, and/or multiple myeloma. The potential role of these drugs in other tumor types is still unclear. $^{3,20,29}$ It has been shown that ZOL acid is effective in both osteoblastic and osteolytic lesions of other solid tumors, including lung cancer. ${ }^{22}$ Some authors defend that use of BPs for bone pain is justified with bone pain pathophysiology (which includes mechanical, metabolic, and neuropathic causes) and data from multiple myeloma, and breast and prostate cancers can be extrapolated to other types of cancer. And that the level of evidence is good for lung, prostate, and renal cancers. ${ }^{20}$

\section{What are the best BPs?}

First-generation BPs include etidronate and clodronate. The second generation is represented by PAM and the third generation by ibandronate and ZOL. 1,3,23,24 Second- and thirdgeneration BPs reduce morbidity from bone metastases, especially from multiple myeloma and breast cancer. ${ }^{1,20,33}$ The aminobisphosphonates (ZOL, risedronate, ibandronate, alendronate, and PAM) are generally more potent inhibitors of bone resorption than the simple BPs (etidronate, clodronate, and tiludronate $)^{21}$ and have more durable responses. ${ }^{3,20}$ There is a dose-dependent effect. ${ }^{20}$ For example, a poor response at $60 \mathrm{mg}$ of PAM can be followed by a trial of 90 or $120 \mathrm{mg} .{ }^{22,30}$ A 2001 cost-utility analysis of prophylactic PAM, for prevention of skeletal events in advanced breast cancer, shows a similar increment of cost-effectiveness ratios when compared to adjuvant chemotherapy in node-negative breast cancer or thiazides treatment for mild-to-moderate hypertension. ${ }^{25}$ In August 2001, ZOL was approved for the treatment of an oncology emergency - hypercalcemia. Subsequent studies showed to be approximately two to three times more potent than PAM. ${ }^{22,34}$ Nowadays, ZOL is accepted to be the most effective BP, however, with some inconsistencies. ${ }^{30,31}$ Patients can experience significant improvements in pain control and bone turnover markers with the switch to more potent BPs, like ZOL, in cases of progressive bone metastases or SREs, while on PAM. ${ }^{24}$ Ibandronate is an oral BP with a potential role in patients with myeloma and breast cancer. In two important Phase III trials, patients experienced significantly reduced pain scores. ${ }^{20,24}$ Data on the efficacy of oral BPs (alendronate or ibandronate) in cancer pain are still insufficient. ${ }^{22}$ In pilot study, the association of radiotherapy and ibandronate provided relevant bone pain relief and increased bone density. ${ }^{24} \mathrm{~A}$ synergistic effect of BPs and radiopharmaceutical medications is also suggested in the literature. ${ }^{21} \mathrm{~A}$ UK pharmacoeconomic analysis reveals that the use of BPs in breast cancer patients with bone metastases may lead to improvement on patient outcome and is cost-effective for the National Health Service. ${ }^{24}$ Although no significant cost differences were found between patients receiving $\mathrm{ZOL}$ and those receiving PAM, the shorter time infusion (15 minutes) has advantages to patients and institutions. ${ }^{34}$ Oral ibandronate has the advantage of cost savings associated to the IV infusion and is considered cost-effective in breast cancer. ${ }^{24,34}$

\section{Is denosumab better than BPs?}

ASCO guidelines recommend the use of bone-modifying agents to prevent SREs in patients with metastatic breast cancer with bone metastases. The options are denosumab 120 mg subcutaneously every 4 weeks, IV PAM 90 mg over no less than 2 hours, or ZOL $4 \mathrm{mg}$ over no less than 15 minutes every 3-4 weeks. ${ }^{21}$ A meta-analysis including six randomized controlled trials (enrolling 13,733 patients) conclude that in the presence of bone metastases, denosumab was safer in delaying or preventing SREs and pain progression compared to BPs (with no difference in overall survival). ${ }^{32}$ A study of 2,046 women with metastatic breast cancer compared pain (secondary outcome) between denosumab and ZOL. No meaningful difference in improvement in pain severity or time, to improvement of pain, was found between these groups. But there was a decrease in pain severity, less functional impairment secondary to pain, and fewer needed to escalate to strong opioid analgesics in the denosumab group. ${ }^{3}$ Denosumab appears to be more convenient than BPs but substantially more expensive and without survival impact. ${ }^{3}$ The guidelines do not offer clear recommendations regarding selection of BTAs but some authors refer that the mechanism of action of denosumab may be one advantage. As 
a circulating antibody, denosumab may reach more sites in the bone than BPs. They have a strong affinity for hydroxyapatite and sites of active bone turnover, a fact leading to a potential reduction in their distribution across the whole skeleton. ${ }^{31}$

\section{It is still a role to calcitonin?}

Calcitonin acts through inhibition of osteoclastic activity, decreases calcium and phosphate resorption by renal tubules, and increases excretion of sodium, potassium, and magnesium. ${ }^{24}$ Calcitonin has been used in the management of bone cancer pain..$^{21}$ The most frequent routes of administration are intranasal spray and subcutaneous injection..$^{21}$ This compound seems to have a limited activity in the treatment of painful bone metastases and the rapid development of tachyphylaxis, which raises safety concerns. ${ }^{24}$

\section{What is the optimal duration of BTAs therapy?}

BTAs should be initiated as soon as bone metastases are diagnosed. However, the optimum dose and the duration of treatment is not so clear in the literature. ${ }^{20,31}$ Moreover, frequently ( $19 \%$ for breast cancer and $28 \%$ prostate cancer) the onset of BTAs is delayed until over 3 months after bone metastases were detected. ${ }^{31}$ The main reasons given for this are a very recent diagnosis and a notion of low risk of bone complications. ${ }^{31}$ To the best of our knowledge, no guidance strategy has been published regarding which patients may be considered at low risk for SREs or bone pain. At the clinical level, only cases of a small number of nonlytic lesions in lowrisk regions may be considered at low risk for SREs or bone pain. However, even patients with mild or no pain appear to benefit from bone-targeted therapy. ${ }^{31}$ The majority of guidelines recommend BTAs in all patients with bone metastases, regardless of whether bone pain is present because of their efficacy in delaying SREs. ${ }^{29,31,35,36}$ Clinical practice guidelines usually recommend continuing use throughout the course of the disease, especially if patients have progression of MBD or a recent SRE and/or elevated bone resorption markers. Adverse events like hypocalcemia, renal function impairment, and presence of osteonecrosis of the jaw may justify unplanned discontinuation. ${ }^{31}$ Another reason is primary tumor progression or completion of preplanned treatment. ${ }^{31}$ A 2017 systematic review does not recommend the use of BTAs in the management of bone pain in cancer patients with a short life expectancy. The level evidence for pain relief in the short term is weak and does not justify the risk of side effects. The author's point that the minimum expected survival time in which cancer patients could benefit from BTAs treatment, to prevent skeletal events, needs to be elucidated in future research. ${ }^{29}$ The same is true for the appropriate duration of administration of these drugs and the management of these patients following treatment withdrawal. ${ }^{31}$ It has been proposed by some authors that an initial high dose of PAM IV (120 mg) can be given for one or two 4-week cycles, with continuation at a lower dose of $60 \mathrm{mg}$ every 4 weeks in responders. ${ }^{20,25}$ When evaluating the risk vs the benefit of long-term BTA therapy, several aspects should be taken into account. The potential for SRE prevention, the patient's renal function, late risk of osteonecrosis of the jaw, but also patient preferences, the need of IV access, and close monitorization are some of them. ${ }^{31,32} \mathrm{~A}$ wide variety of bone metastasis treatments are available, each one having its role in the management of painful bone metastases. Radiotherapy remains the mainstay of treatment with or without surgery, in opioid-refractory patients (radiopharmaceuticals can also be used). ${ }^{1}$

What are the most relevant side effects and drug interactions of BTAs? If patient has renal failure is it not possible to treat with BTAs?

BPs have been associated with acute phase reactions and mild side effects, especially gastrointestinal symptoms (such as dyspepsia, constipation, anorexia, nausea, and diarrhea), ocular inflammation, fever, and myalgias (flu-like syndrome). ${ }^{3,20-22}$ These early complications, due to the release of proinflammatory cytokines, are dose related and typically transitory. ${ }^{22,23}$ This class of drugs may affect the electrolyte balance and renal function in patients. It is recommended to regularly follow up on creatinine clearance and serum calcium, phosphate, potassium, and magnesium levels. ${ }^{21,22}$ BPs will rarely cause nephrotoxicity, usually following relatively rapid infusions. ${ }^{21,22,25}$ Patients need to be well hydrated to minimize nephrotoxicity and consider monitoring renal function postinfusion if necessary. ${ }^{22,23,27}$ Although almost always transitory, many solutions can be indicated in case of persistent or baseline impaired renal function: changing to other agent, adjustment of ZOL dose to the creatinine clearance, more prolonged infusions of PAM, and increased interval of time between administrations (4-6 weeks, 3-6 months). ${ }^{21,22,25}$ In the presence of patients with severe renal impairment (creatinine clearance $<30 \mathrm{~mL} / \mathrm{min}$ ), any of these solutions are indicated. Approximately $70 \%$ of BPs are eliminated by the kidney, and the remainder being taken up by bone (half-life elimination $21-35$ hours). ${ }^{22}$

Older patients require careful titration of BPs similar to others drugs like opioids or sedatives. ${ }^{23}$ Recently, several studies have examined (or are examining) the possible feasibility 
of reducing the dosing frequency to every 12 weeks. Data suggest that the 12-week regimen may become a future standard of care, but bone pain-related outcomes and QoL were not assessed in all studies. Thus, further trials or more mature data are needed. ${ }^{31}$ Most common medication interactions with BPs are with aminoglycosides and phosphate supplements (may increase risk of hypocalcemia) and NSAIDs (increased risk of gastric ulceration). ${ }^{3}$ Denosumab is administered subcutaneously and is not renally excreted (half-life elimination $\sim 28$ days). Most common toxicities are acute phase reactions, fatigue, headache, nausea, skin rash, and hypocalcemia (major precaution). ${ }^{3}$ Adverse events (including osteonecrosis of the jaw) are generally similar between the denosumab and BPs except for increased hypocalcemia and less nephrotoxicity with denosumab. ${ }^{3}$ Most common medication interactions with denosumab are immunosuppressive drugs, leading to higher risk of infection. ${ }^{3}$ These may explain why one subgroup analysis (in one study) suggested that patients with multiple myeloma may have increased mortality rate with denosumab. ${ }^{3}$ Calcitonin's most common side effects are nausea and skin hypersensitivity. ${ }^{21}$ The most feared complication of BTAs is osteonecrosis of the jaw that can be considered rare (with an estimated risk of incidence between $0.7 \%$ and $12 \%) .3,21,23,27,28$ The impact on QoL can be such that it has more disturbing consequences than oncologic disease itself. It is more likely to occur in patients with poor oral hygiene or after dental surgery. ${ }^{3}$ Guidelines suggest that full dental evaluation is mandatory prior to the begging of BP and denosumab therapy. ${ }^{21}$

\section{Conclusions}

This paper reminded us of the big steps of implementing BPs treatment. Actual guidelines are based on low-to-moderatequality evidence, derived from pain trials, where pain was not the principal outcome or that explicitly evaluate QoL. Pain-related outcomes were often not evaluated using standardized and comparable assessment tools. Despite this fact, nowadays BPs are widely used in palliative setting. Even with the introduction of a new class of drugs, the monoclonal antibody against RANKL, BPs (particularly ZOL) are still the first choice because of its historical evidence and because they are less expensive than denosumab. However, denosumab has the advantage of not needing IV access and so less indirect cost with nursing and pharmacy. The more frequent adverse events of the BPs are acute phase reactions, gastrointestinal and flu-like symptoms, renal impairment, and osteonecrosis of jaw. Renal impairment can be managed with correction of other risk factors like dehydration, correction of hydroelectrolyte imbalances, and avoiding other drugs with potential nephrotoxicity. Smaller doses, bigger perfusion time, and bigger intervals between administrations are often needed. Some patients with bad dental status and renal impairment will not be good candidates to BTAs. Denosumab can be an option in some cases of renal impairment but they have the same need of careful evaluation of dental health. BTAs benefit in decreasing the number of skeletal morbidity, including bone pain and SREs, and disease progression need to be weighed against the increased risk of renal impairment, osteonecrosis of jaw, and other adverse events. External beam radiotherapy and orthopedic surgery are local techniques that can be applied to control pain, treat fractures, and prevent another SRE from bone metastasis (radiotherapy is often cheaper and more effective for palliating locoregional bone metastases). Radiopharmaceuticals may also be used with the goal of pain palliation in opioid-refractory pain and in cases of great metastatic tumor burden. This research does not focus extensively on these aspects because BTAs' indications are not exactly the same of them. The major limitation of this research concerns fundamentally the limitations imposed on bibliographic research. As often referred to in similar works, patient preferences, direct comparison of different drugs and different routes of drug administration, and the side effects of analgesics and anticancers treatments are often forgotten in BTAs research. In adjuvant scenario, the data are mainly related to breast cancer. However, in palliative scenario, BPs are used in all bone metastases, unrelated with the primary neoplasm. Therefore, we may consider that the preventive role of these drugs is still underused and future research is needed. If we could have a better control of adverse events, the use of BTAs in adjuvant or in the preventive setting would be easier. Data population studies can also be to explore, because some evidence is emerging of ZOL treatment of osteoporosis in noncancer treatment. It is important to remember that BPs should be prescribed in the majority of the cases, at the moment of diagnosis of bone metastasis and after a dental examination. Delayed prescription can be responsible for the progression of the disease and an increase of cancer pain or the number of SREs.

\section{Acknowledgments}

This work was developed as part of a project selected as an internal clinical research project of Francisco Gentil Portuguese Institute of Oncology, Porto, Portugal (Bulletin 8/2017, CIIPOP 70/2017) and of YOuR Project - a Research Scholarship in Metastatic Breast Cancer from the Portuguese Society of Oncology (September, 2017). Thanks to Luísa Ribeiro from the library services of Francisco Gentil Portuguese Institute of Oncology, Porto. 


\section{Author contributions}

All authors contributed toward data analysis, drafting and critically revising the paper, gave final approval of the version to be published, and agree to be accountable for all aspects of the work.

\section{Disclosure}

The authors report no conflicts of interest in this work.

\section{References}

1. O'Toole GC, Boland P. Metastatic bone cancer pain: etiology and treatment options. Curr Pain Headache Rep. 2006;10(4):288-292.

2. Bell R. Efficacy of ibandronate in metastatic bone disease: review of clinical data. Oncologist. 2005;10(Suppl 1):8-13.

3. Vardy J, Agar M. Nonopioid drugs in the treatment of cancer pain. J Clin Oncol. 2014;32(16):1677-1690.

4. Aapro M, Abrahamsson PA, Body JJ, et al. Guidance on the use of bisphosphonates in solid tumours: recommendations of an international expert panel. Ann Oncol. 2008;19(3):420-432.

5. Pavlakis N, Stockler M. Bisphosphonates for breast cancer. Cochrane Database Syst Rev. 2002 (1):CD003474.

6. Coleman RE. Bisphosphonates: clinical experience. Oncologist. 2004;9(Suppl 4):14-27.

7. Small EJ, Smith MR, Seaman JJ, Petrone S, Kowalski MO. Combined analysis of two multicenter, randomized, placebo-controlled studies of pamidronate disodium for the palliation of bone pain in men with metastatic prostate cancer. J Clin Oncol. 2003;21(23):4277-4284.

8. Rosen LS, Gordon DH, Dugan W, et al. Zoledronic acid is superior to pamidronate for the treatment of bone metastases in breast carcinoma patients with at least one osteolytic lesion. Cancer. 2004;100(1):36-43.

9. Rosen LS, Gordon D, Tchekmedyian NS, et al. Long-term efficacy and safety of zoledronic acid in the treatment of skeletal metastases in patients with nonsmall cell lung carcinoma and other solid tumors: a randomized, Phase III, double-blind, placebo-controlled trial. Cancer. 2004;100(12):2613-2621.

10. Kohno N, Aogi K, Minami H, et al. Zoledronic acid significantly reduces skeletal complications compared with placebo in Japanese women with bone metastases from breast cancer: a randomized, placebo-controlled trial. J Clin Oncol. 2005;23(15):3314-3321.

11. Vogel CL, Yanagihara RH, Wood AJ, et al. Safety and pain palliation of zoledronic acid in patients with breast cancer, prostate cancer, or multiple myeloma who previously received bisphosphonate therapy. Oncologist. 2004;9(6):687-695.

12. Wardley A, Davidson N, Barrett-Lee P, et al. Zoledronic acid significantly improves pain scores and quality of life in breast cancer patients with bone metastases: a randomised, crossover study of community vs hospital bisphosphonate administration. $\mathrm{Br} J$ Cancer. 2005;92(10):1869-1876.

13. Saad F, Gleason DM, Murray R, et al. A randomized, placebo-controlled trial of zoledronic acid in patients with hormone-refractory metastatic prostate carcinoma. J Natl Cancer Inst. 2002;94:1458-1468.

14. Rosen LS, Gordon D, Tchekmedyian S, et al. Zoledronic acid versus placebo in the treatment of skeletal metastases in patients with lung cancer and other solid tumors: a phase III, double-blind, randomized trial--the Zoledronic Acid Lung Cancer and Other Solid Tumors Study Group. J Clin Oncol. 2003;21(16):3150-3157.
15. Rosen LS, Gordon D, Kaminski M, et al. Zoledronic acid versus pamidronate in the treatment of skeletal metastases in patients with breast cancer or osteolytic lesions of multiple myeloma: a phase III, doubleblind, comparative trial. Cancer J. 2001;7(5):377-387.

16. Gralow J, Tripathy D. Managing metastatic bone pain: the role of bisphosphonates. J Pain Symptom Manage. 2007;33(4):462-472.

17. Hadi S, Fan G, Hird AE, Kirou-Mauro A, Filipczak LA, Chow E. Symptom clusters in patients with cancer with metastatic bone pain. J Palliat Med. 2008;11(4):591-600.

18. Hadi S, Zhang L, Hird A, de Sa E, Chow E. Validation of symptom clusters in patients with metastatic bone pain. Curr Oncol. 2008;15(5):211-218.

19. Carr DB, Goudas LC, Balk EM, Bloch R, Ioannidis JP, Lau J. Evidence report on the treatment of pain in cancer patients. J Natl Cancer Inst Monogr. 2004(32):23-31.

20. Davis MP, Walsh D, Lagman R, Legrand SB. Controversies in pharmacotherapy of pain management. Lancet Oncol. 2005;6(9): 696-704.

21. Mitra R, Jones S. Adjuvant analgesics in cancer pain: a review. Am J Hosp Palliat Care. 2012;29(1):70-79.

22. Lussier D, Huskey AG, Portenoy RK. Adjuvant analgesics in cancer pain management. Oncologist. 2004;9(5):571-591.

23. Mercadante S, Arcuri E. Pharmacological management of cancer pain in the elderly. Drugs Aging. 2007;24(9):761-776.

24. Mercadante S, Fulfaro F. Management of painful bone metastases. Curr Opin Oncol. 2007;19(4):308-314.

25. Mcdonnell FJ, Sloan JW, Hamann SR. Advances in cancer pain management. Curr Pain Headache Rep. 2001;5(3):265-271.

26. Oura S, Hirai I, Yoshimasu T, Kokawa Y, Sasaki R. Clinical efficacy of bisphosphonate therapy for bone metastasis from breast cancer. Breast Cancer. 2003;10(1):28-32.

27. Macherey S, Monsef I, Jahn F, et al. Bisphosphonates for advanced prostate cancer. Cochrane Database Syst Rev. 2017;12(12): CD006250.

28. O'Carrigan B, Wong MH, Willson ML, Stockler MR, Pavlakis N, Goodwin A. Bisphosphonates and other bone agents for breast cancer. Cochrane Database Syst Rev. 2017;10(10):CD003474.

29. Porta-Sales J, Garzón-Rodríguez C, Llorens-Torromé S, Brunelli C, Pigni A, Caraceni A. Evidence on the analgesic role of bisphosphonates and denosumab in the treatment of pain due to bone metastases: a systematic review within the European Association for Palliative Care guidelines project. Palliat Med. 2017;31(1):5-25.

30. Kongsgaard U, Kaasa S, Dale O, et al. Palliative Treatment of CancerRelated Pain. Oslo, Norway: Knowledge Centre for the Health Services at The Norwegian Institute of Public Health (NIPH);2005.

31. von Moos R, Costa L, Ripamonti CI, Niepel D, Santini D. Improving quality of life in patients with advanced cancer: targeting metastatic bone pain. Eur J Cancer. 2017;71:80-94.

32. Chen F, Pu F. Safety of denosumab versus zoledronic acid in patients with bone metastases: a meta-analysis of randomized controlled trials. Oncol Res Treat. 2016;39(7-8):453-459.

33. Mitra S, Khandelwal P, Roberts K, Kumar S, Vadivelu N. Pain relief in laparoscopic cholecystectomy: a review of the current options. Pain Pract. 2012;12(6):485-496.

34. Lucas LK, Lipman AG. Recent advances in pharmacotherapy for cancer pain management. Cancer Pract. 2002;(10 Suppl 1):s14-s20.

35. Ripamonti CI, Santini D, Maranzano E, Berti M, Roila FESMO Guidelines Working Group. Management of cancer pain: ESMO clinical practice guidelines. Ann Oncol. 2012;23(Supp1 7):vii139-vii154.

36. Benedetti C, Brock C, Cleeland C, et al. NCCN practice guidelines for cancer pain. Oncology (Williston Park). 2000;14:135-150. 


\section{Publish your work in this journal}

Cancer Management and Research is an international, peer-reviewed open access journal focusing on cancer research and the optimal use of preventative and integrated treatment interventions to achieve improved outcomes, enhanced survival and quality of life for the cancer patient. The manuscript management system is completely online and includes a very quick and fair peer-review system, which is all easy to use. Visit http://www.dovepress.com/testimonials.php to read real quotes from published authors. 